\title{
Development and Standardization of Rapid and Efficient Seed Germination Protocol for Cannabis sativa
}

Aleksei Sorokin\#, Narendra Singh Yadav ${ }^{\#}$, Daniel Gaudet and Igor Kovalchuk*

Department of Biological Sciences, University of Lethbridge, Lethbridge T1K 3M4, Alberta, Canada

\#Contributed equally to this work

*For correspondence: igor.kovalchuk@uleth.ca

\begin{abstract}
[Abstract] Cannabis seed germination is an important process for growers and researchers alike. Many biotechnological applications require a reliable sterile method for seed germination. This protocol outlines a seed germination procedure for Cannabis sativa using a hydrogen peroxide $\left(\mathrm{H}_{2} \mathrm{O}_{2}\right)$ solution as liquid germination media. In this protocol, all three steps including seed sterilization, germination, and seedlings development were carried out in an $\mathrm{H}_{2} \mathrm{O}_{2}$ solution of different concentrations; $1 \% \mathrm{H}_{2} \mathrm{O}_{2}$ solution showed the fastest and the most efficient germination. This protocol also exhibited high germination efficiency for very old cannabis seeds with lower viability. Overall, this protocol demonstrates superior germination compared to water control and reduces the risk of contamination, making it suitable for tissue culture and other sensitive applications.
\end{abstract}

Keywords: Cannabis sativa, Rapid germination, Hydrogen peroxide, Seed sterilization, Seedling development

[Background] Cannabis sativa, otherwise known as marijuana or hemp, is an annual primarily dioecious flowering plant in which male/female sex is determined by heteromorphic chromosomes $(X$ and Y) (Gaudet et al., 2020). Cannabis is grown for a variety of agricultural uses; nearly all parts of cannabis plant are used, seeds for food, stem for fiber, and flowers/leaves for medicine. Flowers produce a mix of cannabinoids and aromatic compounds valued for their therapeutic and recreational effects (Chandra et al., 2017). Cannabis plants are propagated either clonally through cuttings or via seed germination. Seed germination is very important for researchers, breeders, and growers alike, especially since seeds from elite cultivars can be very expensive and valuable. Additionally, older seeds may have a reduced germination rate while bacterial and fungal contamination can compromise germination, especially when seeds are germinated for tissue culture propagation. To address these issues, we have developed a rapid, sterile, and efficient seed germination protocol using a 1\% hydrogen peroxide $\left(\mathrm{H}_{2} \mathrm{O}_{2}\right)$ solution. In this protocol, all three steps including seed sterilization, germination, and seedlings development were carried out in a $1 \% \mathrm{H}_{2} \mathrm{O}_{2}$ solution. This presents a significant advantage over other sterilants, such as mercuric chloride or bleach, which require additional washing of seeds and a separate germination step on MS solid medium. Our protocol resulted in faster germination and increased seed germination percentage as compared to water control, with no bacterial or fungal contamination, making it suitable for tissue culture and other sensitive applications. In comparison to previous germination methods which take between 4-7 days for radicle appearance and 5-15 days for seedling development 
(Wielgus et al., 2008 and references therein), our germination method resulted in radicle appearance in 1 day and allowed us to obtain cannabis seedlings in a very short period (3-7 days) with minimal efforts. This protocol is also very efficient for germination of very old cannabis seeds with lower viability.

\section{Materials and Reagents}

A. Biological materials

1. Cannabis sativa (Finola, X59, and Blueberry varieties) seeds All seeds were harvested in our laboratory. Blueberry seeds were not older than 6 months, when employed in the experiments. Finola and X59 seeds were more than 5 years old.

B. Chemicals

1. Hydrogen Peroxide $30 \%$ (Merck $^{\circledR}$, catalog number: 1072091000 )

2. Murashige \& Skoog Basal Medium with Vitamins (PhytoTechnology Laboratories ${ }^{\circledR}$, catalog number: M519)

3. Sucrose (Sigma-Aldrich, catalog number: S0389)

4. MES (Sigma-Aldrich, catalog number: M3671)

5. Agar type E (Sigma-Aldrich, catalog number: A4675)

6. MS solid media (1 L) (see Recipes)

C. Plasticware

1. Sterile empty $100 \times 15 \mathrm{~mm}$ Petri plates (VWR International, catalog number: 25384-342)

2. Sterile disposable 15 or $50 \mathrm{ml}$ screw-cap centrifuge tubes (BD, Falcon ${ }^{\mathrm{TM}}$, catalog number: 352070)

\section{Equipment}

1. Laminar flow hood (Microzone Bio Klone 2, catalog number: 30193-086)

2. pH meter (Corning Model 430, catalog number: 475303)

3. Sterile forceps and scalpel (sterilized by heat treatment using a Bunsen burner)

4. Growth chamber (Sanyo MLR-350, catalog number: 859-600-06): $24{ }^{\circ} \mathrm{C}, 18 \mathrm{~h}$ light/6 h dark cycle, light intensity $200 \mu \mathrm{mol} \cdot \mathrm{m}^{-2} \cdot \mathrm{sec}^{-1}$

5. Pro-Mix HP Mycorrhizae Growing Medium (Pro-Mix, catalog number: 20381RG)

\section{Procedure}

\section{Seed germination assay}

1. Soak seeds overnight in various concentrations of hydrogen peroxide solution (liquid germination media or germination solutions) as well as in sterile water control $\left(\mathrm{H}_{2} \mathrm{O}, 1 \% \mathrm{H}_{2} \mathrm{O}_{2}\right.$, 
$3 \% \mathrm{H}_{2} \mathrm{O}_{2}, 5 \% \mathrm{H}_{2} \mathrm{O}_{2}$, or $10 \% \mathrm{H}_{2} \mathrm{O}_{2}$ ) in 15 or $50 \mathrm{ml} \mathrm{screw-cap} \mathrm{(Falcon} \mathrm{tube).} \mathrm{Falcon} \mathrm{tubes} \mathrm{with}$ submerged seeds in various germination solutions were kept in the dark at room temperature.

2. Next day, record the percentage of germinated seeds in germination solution (appearance of radicle is considered as germination event) and add fresh respective germination solution after removal of old solution simply by pouring out.

3. Keep seeds soaked in the same solution for 3 more days in the dark at room temperature and record the percentage of germinated seeds every day.

4. Thereafter, germinated seeds/seedlings were transferred with or without seed coats from $\mathrm{H}_{2} \mathrm{O}_{2}$ solution to MS medium plates to observe the growth of $\mathrm{H}_{2} \mathrm{O}_{2}$ solution-germinated seeds/seedlings on MS medium. To transfer, first germinated seeds/seedlings were poured together with $\mathrm{H}_{2} \mathrm{O}_{2}$ solution from the Falcon tube to the empty petri plate. Then seedlings were transferred to sterile paper by using forceps to remove excess $\mathrm{H}_{2} \mathrm{O}_{2}$ solution. Finally, the germinated seeds/seedlings were transferred to MS media plate by using forceps. The whole transfer process has been carried out in the laminar flow hood.

5. Parafilm sealed MS medium plates with germinated seeds/seedlings are then transferred to the growth chamber $\left(24{ }^{\circ} \mathrm{C}, 18 \mathrm{~h}\right.$ light $/ 6 \mathrm{~h}$ dark cycle and light intensity $\left.200 \mu \mathrm{mol} \cdot \mathrm{m}^{-2} \cdot \mathrm{sec}^{-1}\right)$ for 3 days to observe the growth and survival of $\mathrm{H}_{2} \mathrm{O}_{2}$ solution germinated seeds/seedlings on $\mathrm{MS}$ medium.

6. The $\mathrm{H}_{2} \mathrm{O}_{2}$ solution-germinated seeds/seedlings growth was also observed in soil. Pro-Mix HP Mycorrhizae Growing Medium used for soil experiment. The cannabis seeds were soaked in the $\mathrm{H}_{2} \mathrm{O}_{2}$ solution (germination solutions) for four days and thereafter, germinated seeds/seedlings were transferred from $\mathrm{H}_{2} \mathrm{O}_{2}$ solution to soil pot (Pro-Mix HP Mycorrhizae Growing Medium) to observe the growth and survival of $\mathrm{H}_{2} \mathrm{O}_{2}$ solution germinated seeds/seedlings on soil. The soil pots were transferred to the growth chamber $\left(24^{\circ} \mathrm{C}, 18 \mathrm{~h}\right.$ light/ $6 \mathrm{~h}$ dark cycle and light intensity $\left.200 \mu \mathrm{mol} \cdot \mathrm{m}^{-2} \cdot \mathrm{sec}^{-1}\right)$. The photographs were taken on day 12 .

\section{Data analysis}

Mean seed germination percentage under various concentrations of $\mathrm{H}_{2} \mathrm{O}_{2}$ solution as well as water control were calculated in an excel sheet. Data were shown as mean $\pm \mathrm{SE}$.

\section{Results}

In this study, we have described a rapid and efficient seed germination protocol for Cannabis sativa. The brief description of this protocol has been reported in Sorokin et al. (2020). In the current study, we have standardized the optimum concentration of hydrogen peroxide $\left(\mathrm{H}_{2} \mathrm{O}_{2}\right)$ solution media for efficient sterilization and rapid germination. We have tested various concentrations of $\mathrm{H}_{2} \mathrm{O}_{2}$ solution as well as sterile water control $\left(\mathrm{H}_{2} \mathrm{O}, 1 \% \mathrm{H}_{2} \mathrm{O}_{2}, 3 \% \mathrm{H}_{2} \mathrm{O}_{2}, 5 \% \mathrm{H}_{2} \mathrm{O}_{2}\right.$, or $\left.10 \% \mathrm{H}_{2} \mathrm{O}_{2}\right)$ for sterilization and germination efficiency. All three steps of germination (seed sterilization, germination, and seedlings development) were carried out in various concentrations of $\mathrm{H}_{2} \mathrm{O}_{2}$ solution and seeds were 
kept in liquid media for four days. Hydrogen peroxide presents several significant advantages over mercuric chloride or bleach sterilants, which require additional seed washing, and separate germination/seedling development step in Murashige and Skoog (MS) agar medium (Sorokin et al., 2020). The $1 \% \mathrm{H}_{2} \mathrm{O}_{2}$ solution showed rapid and higher germination than higher $\mathrm{H}_{2} \mathrm{O}_{2}$ concentrations solution and water control at day 1 (Figure 1). On day $1,1 \% \mathrm{H}_{2} \mathrm{O}_{2}$ solution exhibited $82.5 \%$ germination as compared to $22.5 \%$ germination for $3 \% \mathrm{H}_{2} \mathrm{O}_{2}$ group, $17.5 \%$ germination for $5 \% \mathrm{H}_{2} \mathrm{O}_{2}$ group and $47.5 \%$ germination in water control group (Figure 1B). Interestingly, $10 \% \mathrm{H}_{2} \mathrm{O}_{2}$ did not show any germination on day 1 due to its toxic effect (Figure 1). In $1 \% \mathrm{H}_{2} \mathrm{O}_{2}$ solution, radicle appearance (germination) occurred within $24 \mathrm{~h}$ and seedling development (two fully developed cotyledons and two immature true leaves stage) occurred in 72-96 h (Figure 1A). In comparison to previous germination methods which take between 4-7 days for radicle appearance and 5-15 days for seedling development (Wielgus et al., 2008 and references therein), our germination method resulted in radicle appearance in 1 day and allowed us to obtain cannabis seedlings in a very short period (3-7 days) with minimal efforts (Figures 1-2). Considering the possible toxic effect of $\mathrm{H}_{2} \mathrm{O}_{2}$ (since germinated seeds/seedlings stayed continuously in $\mathrm{H}_{2} \mathrm{O}_{2}$ solution for 4 days), we have checked further survival of germinated seeds/seedlings on MS media and soil (Figures 2-3). On MS media, $1 \% \mathrm{H}_{2} \mathrm{O}_{2}$ solution seedlings survived better than other treatments (Figure 2). The water germinated seeds exhibited contamination and did not survive on MS media (Figure 2). Similarly, due to the toxic effect of higher concentration of $\mathrm{H}_{2} \mathrm{O}_{2}$, the $10 \% \mathrm{H}_{2} \mathrm{O}_{2}$ germinated seeds did not survive on MS media (Figure 2). The $1 \% \mathrm{H}_{2} \mathrm{O}_{2}$ solution seedlings also survived well on soil (Figure 3). Apart from this, we have also tested our method for more than 5 -years old cannabis seeds with lower viability, which demonstrated that $1 \% \mathrm{H}_{2} \mathrm{O}_{2}$ solution medium exhibited a very high germination percentage $(\sim 50 \%)$ as compared to water control ( 10\%) (Figure 4). In conclusion, we have developed a rapid and efficient method for $C$. sativa seed germination under sterile conditions for tissue culture and other sensitive applications. 


\section{bio-protocol
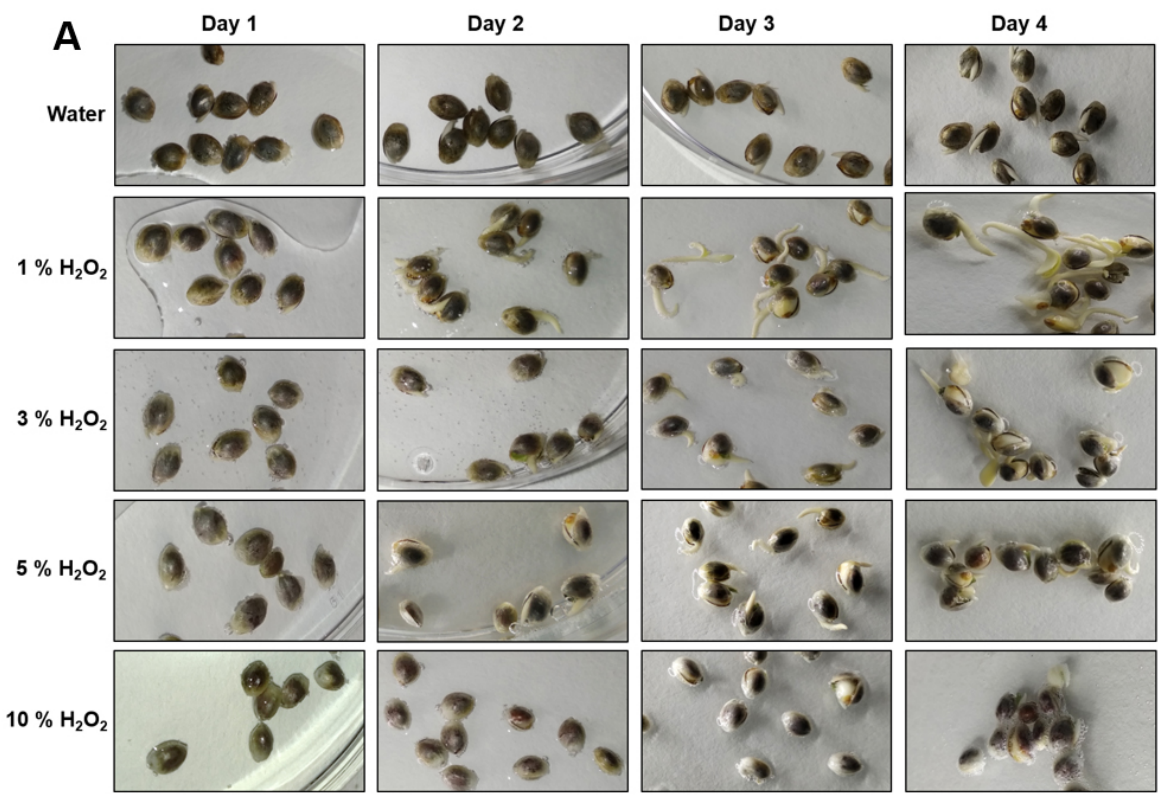

B

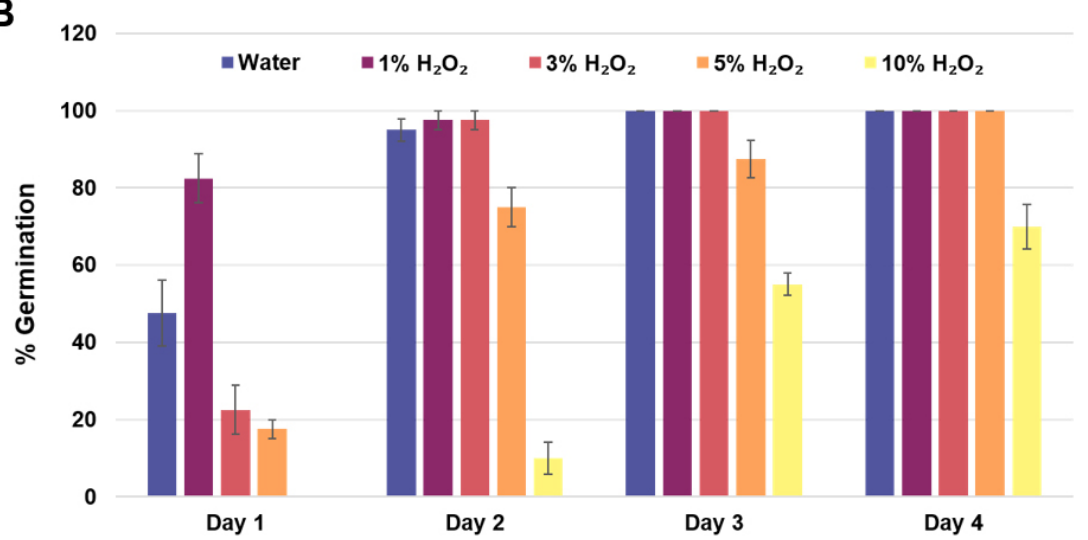

Figure 1. Germination of 6-month-old seeds of Blueberry variety in various concentrations of hydrogen peroxide solution and water control. A. Representative photographs of germinated seeds/seedlings in the $\mathrm{H}_{2} \mathrm{O}_{2}$ solution of various concentrations or water control on day 1 to day 4. B. Comparison of germination percentage between the various concentrations of $\mathrm{H}_{2} \mathrm{O}_{2}$ solution or water control. Data are shown as mean $\pm \mathrm{SE}(n=4)$. In each replicate, 30 seeds were used. 


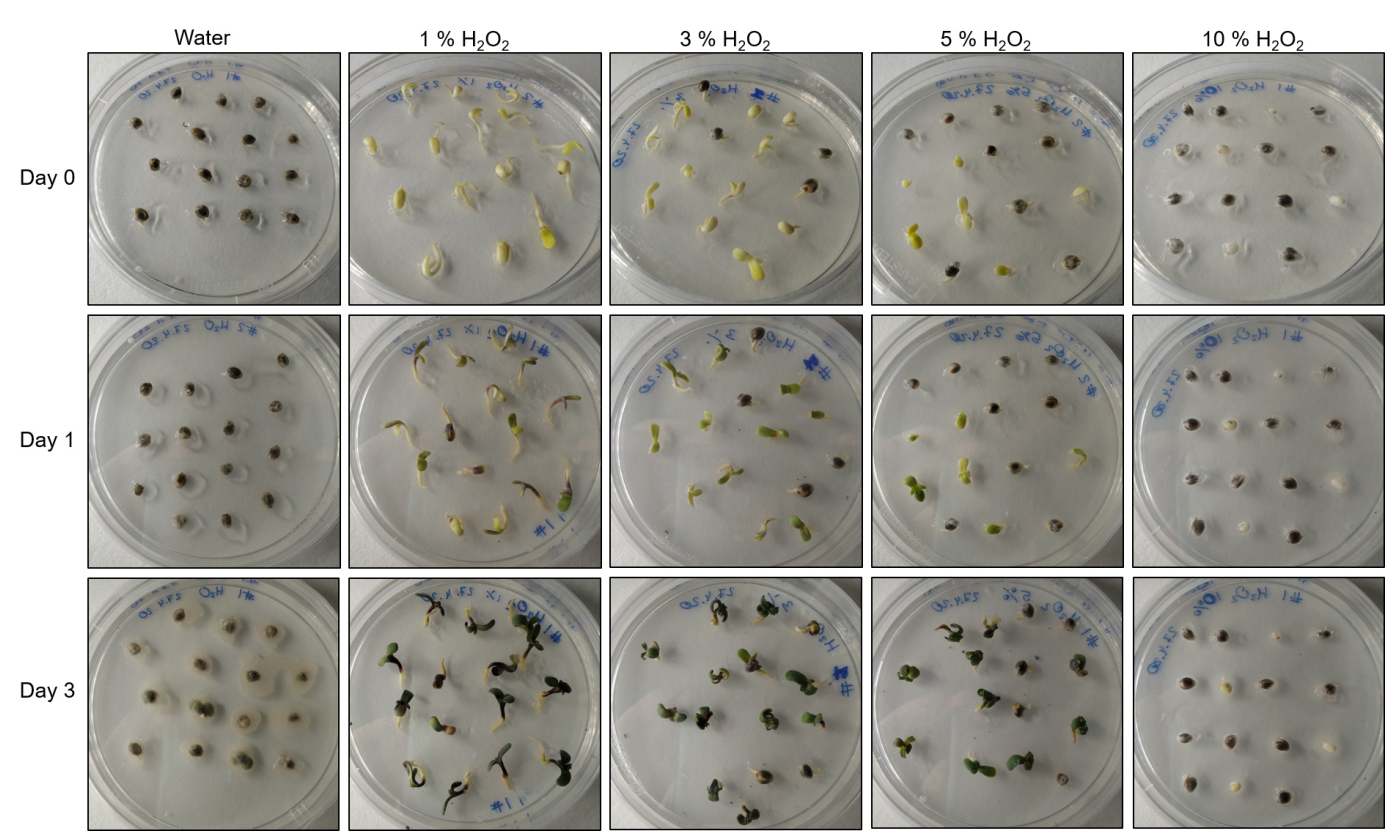

Figure 2. Representative photographs of growth and survival of $\mathrm{H}_{2} \mathrm{O}_{2}$ solutions germinated seeds/seedlings of Blueberry variety on MS media. The Blueberry variety seeds were soaked in the $\mathrm{H}_{2} \mathrm{O}_{2}$ solution (germination solutions) for four days and thereafter, germinated seeds/seedlings were transferred from $\mathrm{H}_{2} \mathrm{O}_{2}$ solution to MS medium plates to observe the growth and survival of $\mathrm{H}_{2} \mathrm{O}_{2}$ solution germinated seeds/seedlings on MS medium. The photographs were taken at day 0 (just after transfer to MS medium plates), day 1 (after 24 $\mathrm{h}$ of the transfer to MS medium plates), and day 3 (after $72 \mathrm{~h}$ of the transfer to MS medium plates) on MS media. 


\section{bĭo-protocol}

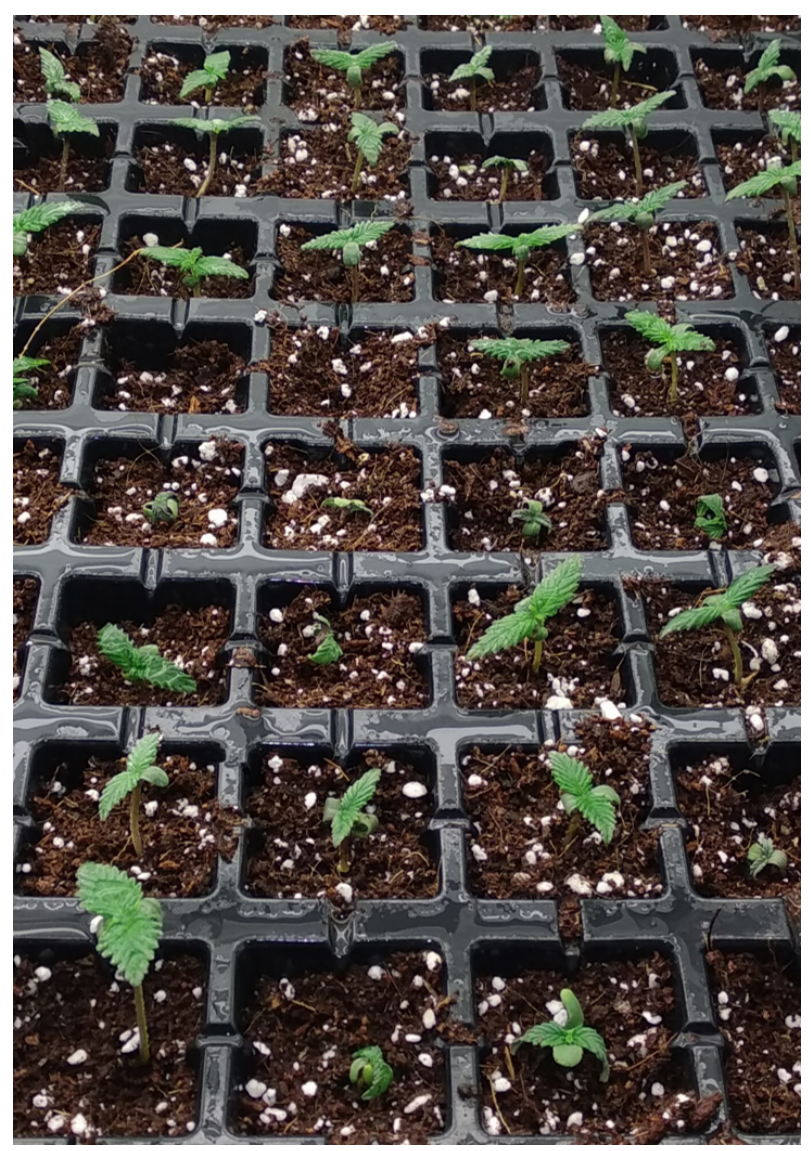

Figure 3. Representative photograph of Blueberry variety young plantlet growing in soil (Pro-Mix HP Mycorrhizae Growing Medium). The Blueberry variety seeds were soaked in the $\mathrm{H}_{2} \mathrm{O}_{2}$ solution (germination solutions) for four days and thereafter, germinated seeds/seedlings were transferred from $\mathrm{H}_{2} \mathrm{O}_{2}$ solution to soil pot (Pro-Mix HP Mycorrhizae Growing Medium) to observe the growth and survival of $\mathrm{H}_{2} \mathrm{O}_{2}$ solution germinated seeds/seedlings on soil. The photographs were taken on day 12 .

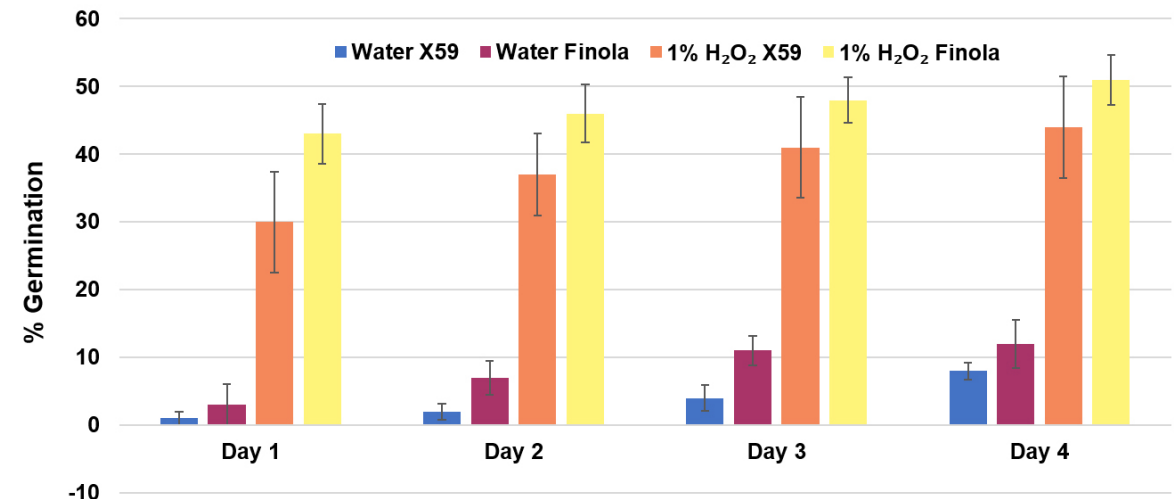

Figure 4. Germination of 5-years old seeds of Finola and X59 varieties in 1\% hydrogen peroxide solution and water control. Comparison of germination percentage between $1 \%$ $\mathrm{H}_{2} \mathrm{O}_{2}$ solution media and water control. Data are shown as mean $\pm \mathrm{SE}(n=5)$. In each replicate, around 30 seeds were used. 


\section{$\underline{\text { Recipes }}$}

1. MS solid media ( $1 \mathrm{~L})$

$4.43 \mathrm{~g}$ Murashige \& Skoog Basal Medium with Vitamins

$500 \mathrm{mg}$ MES

$30 \mathrm{~g}$ Sucrose

$8 \mathrm{~g}$ Agar

Adjust $\mathrm{pH}$ to 5.7 with $\mathrm{KOH}$ and sterilize by autoclaving at $121^{\circ} \mathrm{C}$ for $40 \mathrm{~min} .25 \mathrm{ml}$ of MS media on each Petri plate.

\section{Acknowledgments}

This protocol is derived from Sorokin et al. (2020). We thank the Natural Sciences and Engineering Research Council of Canada (NSERC) and MITACS for funding our work.

\section{Competing interests}

The authors declare that they have no competing interests.

\section{$\underline{\text { References }}$}

1. Chandra, S., Lata, H. and ElSohly, M. A. (2017). Cannabis sativa L.-botany and biotechnology. Chandra, S., Lata, H. and ElSohly, M. A. (Eds.). Springer International Publishing: Cham, Switzerland. ISBN: 9783319545639.

2. Gaudet, D., Yadav, N. S., Sorokin, A., Bilichak, A. and Kovalchuk, I. (2020). Development and optimization of a germination assay and long-term storage for Cannabis sativa pollen. Plants 9: 665.

3. Sorokin, A., Yadav, N. S., Gaudet, D. and Kovalchuk, I. (2020). Transient expression of the $\beta$ glucuronidase gene in Cannabis sativa varieties. Plant Signal Behav 15(8): 1780037.

4. Wielgus, K., Luwanska, A., Lassocinski, W. and Kaczmarek, Z. (2008). Estimation of Cannabis sativa L. tissue culture conditions essential for callus induction and plant regeneration. $J \mathrm{Nat}$ Fibers 5: 199-207. 